\title{
STRATEGI PENGEMBANGAN MONUMEN KAPAL SELAM SEBAGAI DAYA TARIK WISATA DI KOTA SURABAYA
}

\author{
Moch Nur Efendi, A. A. Ngurah Anom Kumbara, IB Ketut Surya \\ Universitas Udayana
}

\begin{abstract}
Monkasel (monument submarine) has been established as one of the heritage tourism attraction in Surabaya city, but it still needs improvement such as maintenance, management, innovation and renewal. This study analyses are management and strategy to develop the submarine monument development as a tourist attraction in Surabaya, East Java. Data obtained through observation, literature, interviews and questionnaires, then analyzed through a likert scale, IE (Internal External) matrix and the SWOT matrix combined with management theory, planning strategy, and SWOT matrix. The study shows that Monkasel as a means of inheritance of historical value and it utilise the management elements, such as Men, Money, Methode, Materials, Machine, Market. that produces matrix calculation IFE and EFE as a basis in determining the strategy and analysis. By using IE matrix and SWOT matrix, so strategy that should be used can be known which is the developer's products and market penetration.
\end{abstract}

Keywords: management, development strategy, herritage tourism, Surabaya.

\begin{abstract}
Abstrak
Wisata Monkasel telah ditetapkan sebagai salah satu daya tarik wisata heritage di kota Surabaya, tetapi masih perlu pembenahan dari segi perawatan, pengelolaan, inovasi dan pembaharuan Monkasel. Artikel ini membahas bagaimana pengelolaan dan strategi pengembangan Monumen Kapal Selam sebagai daya tarik wisata di kota Surabaya, Jawa Timur. Data diperoleh melalui observasi, kepustakaan, wawancara, dan angket, kemudian dianalisis melalui skala likert, pendekatan matrik IE (internal eksternal) dan matrik SWOT. Hasil penelitian menunjukkan bahwa profil Monkasel sebagai sarana warisan nilai sejarah dan pengelolaannya memanfaatkan
\end{abstract}


unsur-unsur manajemen, seperti: Men, Money, Methode, Materials, Machine, Market yang menghasilkan perhitungan matrik IFE dan EFE sebagai dasar dalam menentukan strategi, dan analisis. Selanjutnya dengan menggunakan matrik IE dan matrik SWOT dapat diketahui strategi yang perlu digunakan, yaitu pengembangan produk dan penetrasi pasar.

Kata kunci: manajemen, strategi pengembangan, wisata heritage, Surabaya

\section{Pendahuluan}

Kota Surabaya dalam perkembangannya mengalami perubahan yang sangat pesat. Salah satu dampak negatif dari perubahan tersebut antara lain banyaknya bangunan kuno dan monumen bersejarah yang terlantar dan dirobohkan serta dialih fungsikan sehingga tindakan tersebut dikhawatirkan dapat melenyapkan jati diri dan ciri khas kota Surabaya, salah satu alternatif untuk mempertahankan bangunan kuno dan monumen bersejarah dapat ditempuh dengan cara menjadikannya sebagai destinasi wisata sehingga akan dapat diperoleh keuntungan ganda yaitu bangunan kuno dan monumen bersejarah tetap lestari dan mendapatkan keuntungan ekonomi.

Salah satu usaha menanggulangi permasalahan tersebut diperlukan perencanaan dan strategi yang tepat dalam mengembangkan wisata heritage di kota Surabaya, karena keberadaan dan kelestarian budaya memiliki nilai yang sangat penting bagi upaya pemahaman terhadap perkembangan sejarah dan budaya sebuah bangsa sehingga dapat mempertahankan identitas kota secara berkelanjutan.

Monkasel di Surabaya adalah satu-satunya monumen kapal selam terbesar di Asia yang menggunakan eks dari kapal selam yaitu kapal selam KRI Pasopati 410. Daya tarik dari Monkasel adalah monumen kapal selam ini sendiri kemudian memberikan kontribusi yang berarti banyak bagi masyarakat Surabaya, dengan adanya pendirian monumen kapal selam ini menjadi sarana warisan nilai pendidikan sejarah yang merupakan cermin kebesaran bangsa Indonesia sebagai bangsa bahari sehingga memotivasimasyarakat lebih mengenal dan mencintai sejarah kelautan (Rachmawan 2013).

Ironisnya dalam perkembangannya Monkasel menjadi kurang diakui keberadaannya, khususnya pada saat ini. semenjak maraknya pembangunan mall, sehingga budaya masyarakat mulai berubah menjadi lebih konsumerisme dikalangan remaja sendiri kemudian muncul fenomena baru yang dikenal dengan generasi mall, dimana mereka menghabiskan waktunya untuk sekedar ber-window shopping dan berfantasi tentang kehidupan serba enak dan nyaman, akibatnya kebanyakan dari mereka memiliki pola 


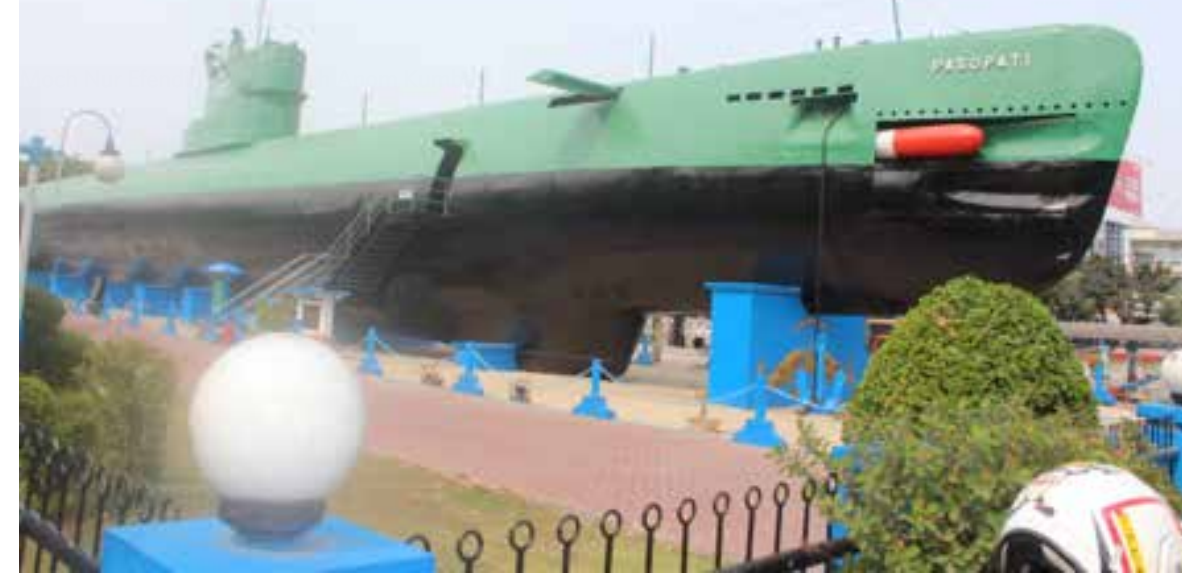

Foto1. Monumen kapal selam Surabaya.

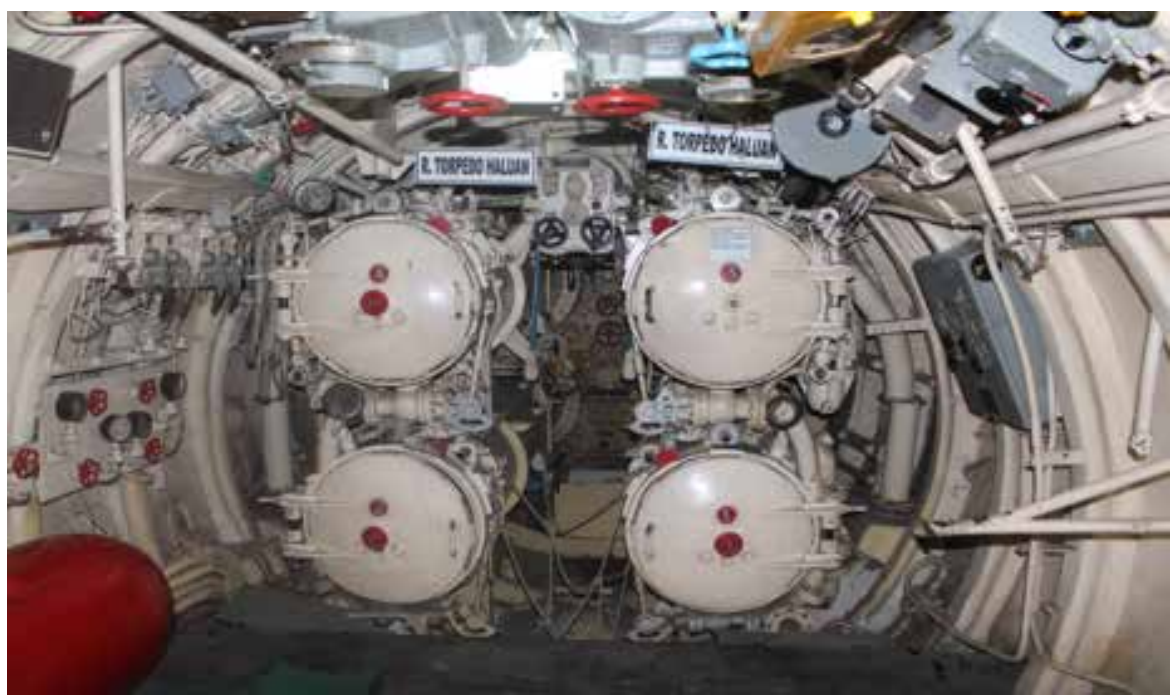

Foto 2. Ruang Torpedo di dalam kapal selam

pikir instan, mencari jalan pintas dan mencari kemudahan-kemudahan tanpa memperhatikan apa yang ada di balik keberhasilan pembangunan yang ada sekarang. Nilai-nilai sejarah perjuangan bangsa mulai diabaikan hingga akhirnya nasionalisme terhadap sejarah perjuangan mulai berkurang hal ini dapat dilihat dari tingginya minat masyarakat untuk berkunjung di mall atau pusat perbelanjaan dibanding berkunjung ke museum atau monumen yang lebih edukatif dan mempunyai nilai sejarah.

Dari fenomena yang terjadi di lapangan belakangan ini, muncul beberapa permasalahan atau kesenjangan antara kenyataan dan harapan permasalahan yang diangkat dalam penelitian ini adalah; 1) Bagaimanakah pengelolaan Monumen Kapal Selam sebagai daya tarik wisata di kota Surabaya? 2) Bagaimana strategi pengembangan Monumen Kapal Selam sebagai daya tarik wisata di kota Surabaya? 


\section{Teori dan Metode}

Untuk menjawab masalah dalam penelitian ini terdapat tiga teori yang sesuai untuk menjawab permasalahan tersebut yaitu strategi perencanaan, SWOT dan teori manajemen.

Pertama, teori perencanaan (Patusuri, 2008:28) untuk mengetahui suatu proses pembuatan keputusan yang berkaitan dengan masa depan, dengan melihat unsur-unsur daya tarik wisata Monkasel dan mengambil langkah atau strategi pengembangannya daya tarik pendukung seperti video rama, kolam renang, skate park dan BMX.

Kedua, teori SWOT (Rangkuti, 2006) Matriks SWOT dapat menggambarkan secara jelas bagaimana peluang dan ancaman eksternalyang dihadapi, dapat disesuaikan dengan kekuatan dan kelemahan yang dimilikinya. Sehingga dapat megetahui strategi apa yang harus dilakukan.

Ketiga, teori manajemen (Manulang, 2012:5) manajemen adalah seni dan ilmu perencanaan, pengorganisasian, penyusunan, pengarahan, pengawasan sumber daya untuk mencapai tujuan yang sudah ditetapkan manajemen yang baik dan efektif menghasilkan keberhasilan dalam suatu organisasi.

Metode penelitian yang digunakan adalah metode penelitian deskriptif kualitatif dan didukung data kuantitatif, dengan teknik pengumpulan data dilakukan dengan observasi, wawancara mendalam, dokumentasi, dan angket. Teknik penentuan sampel menggunakan teknik purposive sampling kemudian dianilisis dengan matrik IFE, EFE, I-E, dan SWOT .

\section{Manajemen Pengelolaan Monkasel di Kota Surabaya}

Struktur organisasi Monkasel berfungsi sebagai kejelasan tanggung jawab, kejelasan kedudukan, kejelasan mengenai jalur hubungan kerja dan kejelasan uraian tugas, sehingga kegiatan-kegiatan yang berbeda bisa dikoordinasikan bisa dilihat pada gambar 1 .

Gambar 1 Struktur Organisasi Pengelolaan Monkasel

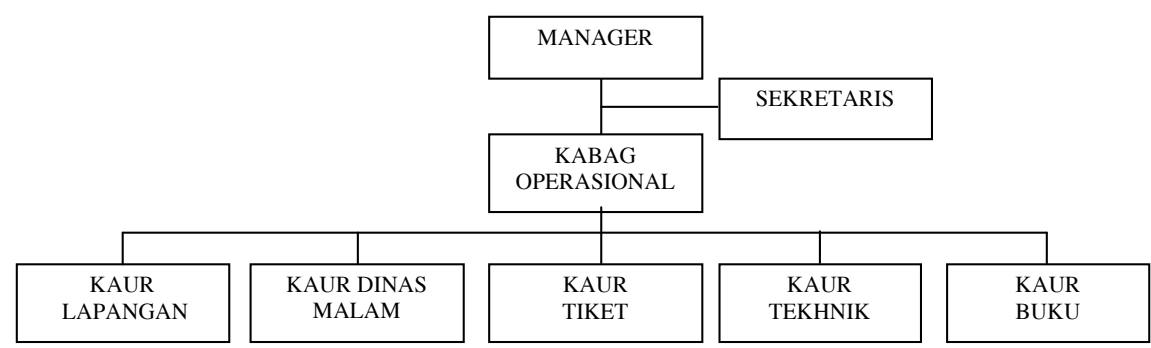

Sumber : Kabag. Monkasel

Setelah dilakukan analisis kinerja pengelola Monkasel :

1. Pihak pengelola kurang kreatif dalam pengembangan bentuk 


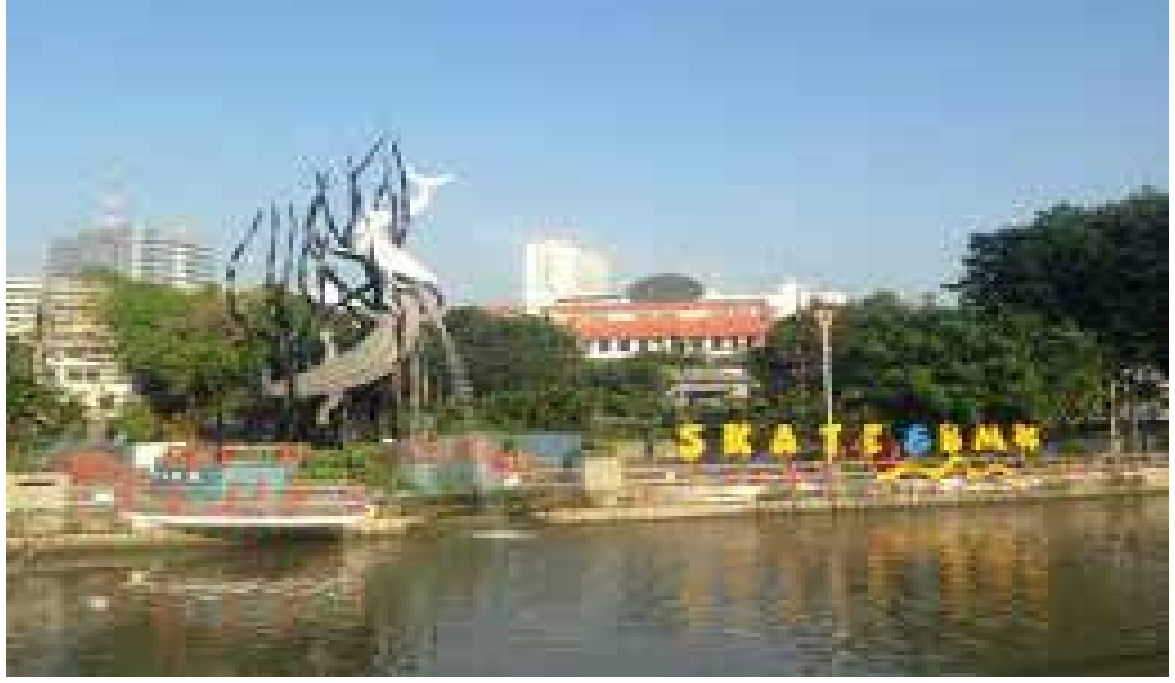

Foto 3. Arena Skate Park \& BMX di Kawasan Monkasel

bangunan penunjang Monkasel seperti halnya gate, loket, toko souvenir, toilet, cafe, pos ijin, panggung hiburan, tempat sampah, serta penunjuk jalan menuju lokasi.

2. Minimnya perawatan Monkasel, seperti warna kapal selam yang kurang menarik dan berkarat karena hal ini merupakan salah satu menjadi daya tarik.

3. Tema yang kurang terkonsep dan spesifik sehingga membuat suasana yang kurang menarik dan membosankan.

4. Masih rendah tingkat SDM dari segi pengetahuan dan pendidikan, sehingga mempengaruhi kinerja dalam pengelolaan Monkasel.

5. Kurangnya inovasi fasilitas atau pembaruan yang dilakukan oleh monkasel seperti taman bermain, kafetaria, live music, WI-fi,dan lainlain.

6. Kurangnya program pendidikan dan pelatihan serta ketersedian tenaga ahli.

7. Penetapan pemilihan media promosi dan saluran distribusi yang kurang efektif.

8. Pengelola belum bisa memanfaatkan sungai di pinggir lokasi Monkasel yang dapat dijadikan wisata alternatif dan transportasi air.

Melalui Forkom (Forum Komunikasi Pengelola Objek Wisata Surabaya) telah dibentuk tim kreatif yang arahnya untuk membuat kegiatan-kegiatan yang bisa mensinergikan objek wisata dengan objek yang lain, memberi pelatihan dan seminar kepada generasi muda tentang wisata agar bisa dinikmati oleh para turis dan memberikan dampak positif, selain itu melalui Forkom sudah dibicarakan dengan beberapa paguyuban seperti reog, ludruk, dan sebagainya. Potensi seniman dan budayawan itu untuk bisa tampil di Monkasel 


\section{Strategi Pengembangan Monkasel Sebagai Daya Tarik Wisata a. Matrik IFE (Internal Factor Evaluation Matrix)}

Tabel 1 Skor Lingkungan Internal Monkasel

\begin{tabular}{|c|c|c|c|c|}
\hline No. & Variabel / Indikator & Bobot & Rating & Skor \\
\hline $\begin{array}{l}1 \\
\mathrm{a} \\
\mathrm{b}\end{array}$ & $\begin{array}{l}\text { Lokasi } \\
\text { Aksesibilitas } \\
\text { Vasibilitas }\end{array}$ & $\begin{array}{l}\mathrm{O}, \mathrm{0} 74 \\
\mathrm{O}, \mathrm{O} 74\end{array}$ & $\begin{array}{l}2,928 \\
2,857\end{array}$ & $\begin{array}{l}0.216 \\
0.211\end{array}$ \\
\hline $\begin{array}{l}2 \\
\mathrm{a} \\
\mathrm{b}\end{array}$ & $\begin{array}{l}\text { Fasilitas } \\
\text { Tersedia sarana pariwisata } \\
\text { Tersedia prasarana pariwisata }\end{array}$ & $\begin{array}{l}0,074 \\
0,071\end{array}$ & $\begin{array}{r}2,929 \\
2,714\end{array}$ & $\begin{array}{l}0,217 \\
0,192\end{array}$ \\
\hline $\begin{array}{l}3 \\
\mathrm{a}\end{array}$ & $\begin{array}{l}\text { Harga } \\
\text { Orientasi penetapan harga/tarif }\end{array}$ & 0,062 & 2,142 & 0,132 \\
\hline $\begin{array}{l}4 \\
\mathrm{a} \\
\mathrm{b}\end{array}$ & $\begin{array}{l}\text { Produk } \\
\text { Keadaan fisik } \\
\text { Nilai sejarah }\end{array}$ & $\begin{array}{l}0,082 \\
0,086\end{array}$ & $\begin{array}{r}3,214 \\
3,5\end{array}$ & $\begin{array}{l}0,263 \\
0,301\end{array}$ \\
\hline & $\begin{array}{l}\text { Pelayanan } \\
\text { Kualitas pelayanan }\end{array}$ & 0,078 & 3,071 & 0,239 \\
\hline $\begin{array}{l}6 \\
\mathrm{a} \\
\mathrm{b}\end{array}$ & $\begin{array}{l}\text { Kegiatan Wisata } \\
\text { Interaksi sosial } \\
\text { Wisata pendidikan \& sejarah }\end{array}$ & $\begin{array}{r}0,071 \\
0,082\end{array}$ & $\begin{array}{l}2,714 \\
3,214\end{array}$ & $\begin{array}{l}0,192 \\
0,263\end{array}$ \\
\hline $\begin{array}{l}7 \\
\mathrm{a} \\
\mathrm{b}\end{array}$ & $\begin{array}{l}\text { SDM } \\
\text { Ketersediaan tenaga ahli } \\
\text { Pendidikan dan pelatihan }\end{array}$ & $\begin{array}{l}0,060 \\
0,064\end{array}$ & $\begin{array}{r}2 \\
2,357\end{array}$ & $\begin{array}{l}0,12 \\
0.15\end{array}$ \\
\hline $\begin{array}{l}8 \\
\mathrm{a} \\
\mathrm{b}\end{array}$ & $\begin{array}{l}\text { Promosi } \\
\text { Pemilihan media promosi } \\
\text { Saluran distribusi }\end{array}$ & $\begin{array}{l}0,061 \\
0,061\end{array}$ & $\begin{array}{l}2,214 \\
2,142\end{array}$ & $\begin{array}{r}0,135 \\
0,13 \\
\end{array}$ \\
\hline & Total & & & 2,716 \\
\hline
\end{tabular}

Sumber : Survey Lapangan dan Wawancara

Dapat diketahui bahwa kekuatan pada Monkasel yang mempunyai nilai tertinggi adalah indikator nilai sejarah pada bangunan, hal tersebut dikarenakan Monkasel dipandang mempunyai nilai filosofis monumental terhadap perjuangan dan kelemahannya terletak pada indikator pemilihan promosi yang kurang efektif.

Setelah dilakukan perhitungan untuk mengevaluasi kekuatan dan kelemahan faktor lingkungan internal Monkasel dengan menggunakan matrik IFE, maka diperoleh nilai faktor lingkungan internal dengan total skor sebesar 2,716. Nilai tersebut menunjukkan bahwa Monkasel berada di atas rata-rata dari keseluruhan strategisnya dalam usaha untuk memanfaatkan kekuatan-kekuatan yang ada dan mengurangi kelemahan-kelemahan yang ada.

\section{Matrik EFE (External Factor Evaluation Matrix)}

Dari Tabel 2 dapat diketahui bahwa yang merupakan peluang adalah dari indikator yang paling tinggi yaitu adanya motivasi pengunjung yang sangat tinggi. Sedangkan yang merupakan ancaman adalah indikator kebijakan pemerintah khususnya tentang wisata herritage yang masih kurang berperan. 
Tabel 2 Skor Lingkungan Eksternal Monkasel

\begin{tabular}{|c|c|c|c|c|}
\hline No. & Variabel / Indikator & Bobot & Rating & Skor \\
\hline 1 & Pengunjung & & & \\
\hline $\mathrm{a}$ & Keanekaragaman pengunjung & 0,076 & 3,071 & 0,233 \\
\hline $\mathrm{b}$ & Motivasi pengunjung & 0,087 & 3,643 & 1,317 \\
\hline \multirow[t]{2}{*}{2} & Teknologi & & & \\
\hline & Kemajuan teknologi & 0,082 & 3,5 & 0,287 \\
\hline 3 & Pesaing & & & \\
\hline a & Keunikan objek & 0,081 & 3,357 & 0,272 \\
\hline $\mathrm{b}$ & Keberadaan objek lain yang sejenis & 0,058 & 2 & 0,116 \\
\hline 4 & Sosial budaya & & & \\
\hline a & Peran serta masyarakat & 0,055 & 1.857 & 0,102 \\
\hline b & Pembinaan masyarakat & 0,053 & 1,786 & 0,095 \\
\hline 5 & Keamanan & & & \\
\hline a & Kondisi politik & 0,08 & 3,357 & 0,269 \\
\hline b & Keamanan sekitar lokasi & 0,079 & 3,286 & 0,26 \\
\hline 6 & Ekonomi & & & \\
\hline a & Pertumbuhan ekonomi & 0,075 & 3,357 & 0,177 \\
\hline $\mathrm{b}$ & Daya beli masyarakat & 0,074 & 3 & 0,222 \\
\hline 7 & Pemerintah & & & \\
\hline a & Kebijakan di bidang pariwisata & 0,06 & 2,143 & 0,129 \\
\hline $\mathrm{b}$ & Kebijakan penetapan hari libur nasional & 0,084 & 3,429 & 0,288 \\
\hline \multirow[t]{3}{*}{8} & Swasta & & & \\
\hline & Mitra kerjasama & 0,056 & 1,786 & 0,1 \\
\hline & Total & & & 2,658 \\
\hline
\end{tabular}

Sumber : Survey Lapangan dan Wawancara

Setelah dilakukan perhitungan untuk mengevaluasi peluang dan ancaman faktor lingkungan eksternal Monkasel dengan menggunakan matrik EFE, maka diperoleh nilai faktor eksternal dengan total skor sebesar 2,658. Nilai tersebut menunjukkan bahwa destinasi berada di atas rata-rata dari keseluruhan posisi strategisnya dalam usaha untuk memanfaatkan peluangpeluang eksternalnya dan menghindari ancaman yang timbul.

\section{c Matrik IE (Internal External Matrix)}

Dari hasilmatrik IFE danmatrik EFE setelahdipetakankedalammatrik IE dapatdiketahuiposisiMonkaselberada di kwadran V (lima) dimanastrategi yang akandigunakanadalahstrategipertahankandanpelihara (hold and maintain strategy) yaitu strategi pengembangan produk dan strategi penetrasi pasar.

\section{d. Matrik SWOT}

Berdasarkan hasil analisis Monkasel dihasilkan strategi pengembangan dan strategi penetrasi pasar.Langkah-langkah dalam implementasi strategi pengembangan produk pada Monkasel adalah:

1. Perlu adanya peraturan yang mengatur, menetapkan dan melindungi secara khusus yang terkait dalam pelestarian bangunan kuno dan monumen bersejarah. 
TOTALNILAIEFE

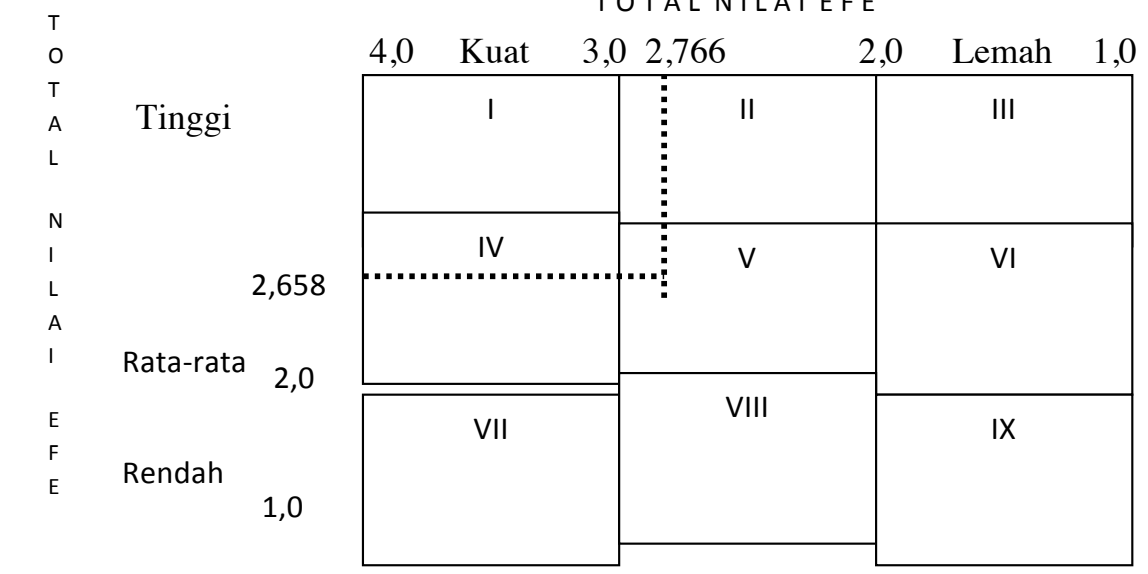

Gambar 2 Matrik Internal-Eksternal (IE) Monkasel

Sumber : Data olahan dari matrik IFE dan matrik EFE.

2. Selain mempunyai keunikan pada bangunannya, guna memberikan daya tarik lain pada Monkasel dilakukan attraksi kesenian daerah setempat. Dengan mengangkat kesenian daerah sebagai suguhan atraksi wisata, ada beberapa hal yang dapat dicapai antara lain mengembangkan, mengangkat, mempopulerkan kreatifitas kesenian daerah dan memberi kesempatan pada masyarakat setempat untuk ikut melestarikan kesenian daerah, mencari penghasilan tambahan. Secara otomatis akan ikut serta meningkatkan kesadaran dalam melestarikan bangunan kuno dan monumen bersejarah

3. Meningkatkan standarisasi kualitas pelayanan dengan cara sedapat mungkin melayani pengunjung dengan sopan, ramah dan sabar. yang dilakukan saat pengunjung mulai masuk di pintu gerbang membeli tiket, memberi informasi sampai mereka pulang. Semua itu dapat dicapai dengan menempatkan petugas lapangan yang terdidik dan terlatih serta betul-betul menguasai kondisi lapangan.

4. Guna meningkatkan daya tarik dan membuat pengunjung betah lebih lama dilokasi perlu Pembaruaan pada bentuk bangunan penunjang Monkasel seperti halnya gate, loket toko souvenir, toilet, cafe, pos, panggung hiburan, tempat duduk dan sarana bermain sesuai tema dan konsep kapal selam.

5. Guna meningkatkan kontribusi pendapatan yang dihasilkan dari penjualan tiket masuk perlu dilakukan penyesuaian harga tiket masuk dengan cara menaikkan besarnya harga tiket masuk pada hari-hari libur.

6. Menjaga agar monumen tetap dalam kondisi baik serta memperbaiki 
Tabel 3 Analisis SWOT Pengembangan Monkasel

\begin{tabular}{|c|c|c|}
\hline & Kekuatan (Strength) & Kelemahan (Weaknesses) \\
\hline Faktor Internal & $\begin{array}{l}\text { 1. Mempunyai nilai sejarah yang } \\
\text { tinggi merupakan daya tarik } \\
\text { utama } \\
\text { 2. Keadaan fisik dan keaslian } \\
\text { bangunan masih terjaga dan } \\
\text { terawat baik } \\
\text { 3. Wisata pendidikan dan sejarah } \\
\text { 4. Kualitas pelayanan } \\
\text { 5. Mempunyai aksesibilitas dan } \\
\text { vasibilitas } \\
\text { 6. Tersedia sarana dan prasarana } \\
\text { 7. Dapat dilakukan kegiatan yang } \\
\text { berinteraksi dengan lingkungan } \\
\text { sosial }\end{array}$ & $\begin{array}{l}\text { 1. Kurangnya tenaga ahli } \\
\text { 2. Program pendidikan dan pelati- } \\
\text { han SDM } \\
\text { 3. Penerapan harga tiket yang } \\
\text { terlalu rendah } \\
\text { 4. Kurang gencarnya kegiatan } \\
\text { promosi } \\
\text { 5. Saluran distribusi belum ber- } \\
\text { peran optimal dalam membantu } \\
\text { memberikan informasi }\end{array}$ \\
\hline Peluang (Opportunities) & Kekuatan dan Peluang (SO) & Kelemahan dan Peluang (WO) \\
\hline $\begin{array}{l}\text { 1. Motivasi pengunjung yang } \\
\text { tinggi } \\
\text { 2. Kebijakan pemerintah dalam } \\
\text { penetapan hari libur nasional } \\
\text { 3. Kemajuan teknologi } \\
\text { 4. Keunikan bangunan merupakan } \\
\text { aset yang tidak dapat ditiru } \\
\text { 5. Kondisi politik negara yang } \\
\text { cukup stabil } \\
\text { 6. Keamanan di sekitar lokasi yang } \\
\text { mendukung } \\
\text { 7. Keanekaragaman pengunjung } \\
\text { memperbesar pasar } \\
\text { 8. Pertumbuhan ekonomi dan } \\
\text { daya beli masyarakat }\end{array}$ & $\begin{array}{l}\text { 1. Membuat keadaan fisik dan } \\
\text { keaslian bangunan yang mem- } \\
\text { punyai nilai sejarah tinggi harus } \\
\text { dijaga dan dilestarikan } \\
\text { 2. Mempertartahankan keunikan } \\
\text { bangunan merupakan aset } \\
\text { yang tidak dapat ditiru perlu } \\
\text { dipertahankan } \\
\text { 3. Meningkatkan kualitas pelay- } \\
\text { anan }\end{array}$ & $\begin{array}{l}\text { 1. Keunikan bangunan merupakan } \\
\text { aset yang tidak dapat di tiru } \\
\text { perlu dipertahankan } \\
\text { 2. Menambah tenaga ahli dalam } \\
\text { pengelolaannya } \\
\text { 3. Meningkatkan frekuensi pelak- } \\
\text { sanaan program pendidkan dan } \\
\text { pelatihan SDM } \\
\text { 4. Meningkatkan kontribusi pen- } \\
\text { dapatan dari penjualan tiket } \\
\text { (Pengembangan Produk) }\end{array}$ \\
\hline Ancaman (Threats) & Kekuatan dan Ancaman (ST) & Kelemahan dan Ancaman (WT) \\
\hline $\begin{array}{l}\text { 1. Kebijakan pemerintah saat ini } \\
\text { belum mendukung pengem- } \\
\text { bangan wisata heritage secara } \\
\text { optimal } \\
\text { 2. Keberadaan obyek lain yang } \\
\text { sejenis merupakan pesaing } \\
\text { 3. Kerja sama dengan pihak } \\
\text { swasta belum memberikan kon- } \\
\text { tribusi yang menguntungkan } \\
\text { 4. Pembinaan da peran sera } \\
\text { masyarakat belum optimal }\end{array}$ & $\begin{array}{l}\text { 1. Melestarikan keunikan dan } \\
\text { keasrian bangunan dengan nilai } \\
\text { sejarah yang tinggi . } \\
\text { 2. Membuat peraturan yang lebih } \\
\text { spesifik tentang pelestarian } \\
\text { bangunan kuno dan monumen } \\
\text { bersejarah. } \\
\text { 3. Meningkatkan kerja sama } \\
\text { dengan pihak swasta agar dapat } \\
\text { memberikan kontribusi yang } \\
\text { menguntungkan } \\
\text { (Penetrasi Pasar) }\end{array}$ & $\begin{array}{l}\text { 1. Menambah Tenaga Ahli dalam } \\
\text { pengelolaan } \\
\text { 2. Meningkatkan program } \\
\text { pendidikan dan pelatihan SDM } \\
\text { sehingga dapat meningkatkan } \\
\text { pelayanan pada pengunjung } \\
\text { 3. Meningkatkan kegiatan promosi } \\
\text { melalui pemilihan media pro- } \\
\text { mosi yang tepat dan menambah } \\
\text { saluran distribusi dalam mem- } \\
\text { berikan informasi } \\
\text { 4. Meningkatkan kerjasama } \\
\text { dengan pihak swasta agar dapat } \\
\text { memberikan kontribusi yang } \\
\text { menguntungkan } \\
\text { 5. Program pembinaan } \\
\text { masyarakat } \\
\text { (Penetrasi Pasar) }\end{array}$ \\
\hline
\end{tabular}

\section{bagian monumen yang sudah mulai rusak sehingga tampak indah dan menarik}

Langkah-langkah implementasi dalam strategi penetrasi pasar pada Monkasel antara lain:

1. Memperluas pasar yang sudah ada melalui saluran distribusi, menyebarkan informasi melalui akses-akses internet.

2. Meningkatkan dan menanamkan rasa kecintaan terhadap kota Surabaya kepada anak-anak sekolah dengan mengadakan kerjasama 
ke sekolah-sekolah untuk di masukkan sebagai program wajib untuk mengunjungi Monkasel dalam menunjang pelajaran sekolah.

3. Meningkatkan pasar luar negeri dengan menambah saluran distribusi yang sudah ada.

\section{Simpulan}

Berdasarkan hasil analisis maka dapat di simpulkan hal-hal sebagai berikut. Pertama, Monkasel sebagai sarana warisan nilai sejarah yang mencerminkan kebesaran Indonesia sebagai bangsa bahari sekaligus menghormati pejuang dan pahlawan laut sekaligus sebagai bukti sejarah pengabdian Korps Hiu Kencana yang bisa menambah destinasi wisata bernuansa bahari dan sejarah, sehingga pengunjung akan mendapatkan nilai pendidikan, pengalaman baru tentang kapal selam dan pengetahuan taentang budaya lokal Surabaya.

Kedua, Pengelolaan Monkasel sudah cukup baik dalam segi pelayanan, perawatan, penambahan attraksi serta promosi. Selain itu melalui Forkom telah dibentuk tim kreatif yang arahnya untuk membuat kegiatan-kegiatan yang bisa mensinergikan objek wisata dengan objek yang lain, memberi pelatihan dan seminar kepada anak-anak muda tentang wisata agar bisa dinikmati oleh para turis dan memberikan dampak positif kepada generasi muda, selain itu melalui Forkom sudah dibicarakan dengan beberapa paguyuban seperti reog, ludruk, dan sebagainya. Potensi seniman dan budayawan itu untuk bisa tampil di Monkasel.

Ketiga, Berdasarkan matrik IFE diperoleh skor 2,766 dan pada matrik EFE diperoleh skor 2,658. Dari hasil perhitungan tersebut dapat digunakan sebagai dasar dalam menentukan strategi, dan analisis dengan menggunakan matrik IE dan matrik SWOT sehingga dapat diketahui bahwa untuk Monkasel berada pada sel V (lima) dengan strategi: pengembangan produk dan penetrasi pasar.

\section{Ucapan Terimakasih}

Penulis menyampaikan terima kasih kepada Prof. Dr. I Nyoman Darma Putra, M. Litt, selaku Ketua Program Studi Magister Kajian Pariwisata Universitas Udayana dan Dr. Ir. Syamsul Alam Paturusi, MSP., sebagai Sekretaris Program Studi Magister Kajian Pariwisata Universitas Udayana. Ucapan terima kasih juga ditujukan kepada Prof. Dr. A. A. Ngurah Anom Kumbara, MS sebagai pembimbing I, Dr. Ida Bagus Ketut Surya, SE., MM. Selaku Pembimbing II yang telah membimbing, mengarahkan, mendorong, dan memberikan semangat sehingga terselesainya artikel ini. Selain itu ucapan terima kasih juga disampaikan kepada para sahabat yang memberikan bantuan dan inspirasi dalam penulisan artikel ini. 


\section{Daftar Pustaka}

Manullang, M. 2012. Dasar-dasar Manajemen. Yogyakarta: Gadjah mada Universitass Press.

Paturusi, Syamsul Alam. 2005. Perencanaan Tata Kawasan Pariwisata. Denpasar: Program Magister Kajian Pariwisata Universitas Udayana.

Rachmawan, Edi. 2013. "Perancangan Branding Fisik Monkasel". Jurnal Desain. Surabaya: Jurusan Desain Produk FTSP-ITS: Institut Tehnik Surabaya

Rahajoe, Rita Poedji. 2007. "Strategi Pengembangan Wisata Heritage Sebagai Daya Tarik Wisata di Kota Surabaya”(Tesis). Denpasar: Program Pascasarjana Universitas Udayana.

Rangkuti, Freddy. 2006. Analisis SWOT Teknik Membedah Kasus Bisnis.Jakarta: PT. Gramedia Pustaka Utama.

\section{Profil Penulis}

Moch Nur Efendi menyelesaikan pendidikan Magister Kajian Pariwisata di Universitas Udayana Denpasar Bali tahun 2016. Dia menyelesaikan program Diploma IV pada tahun 2011 jurusan Manajemen Perhotelan di STP SatyaWidya Surabaya, pengalaman yang dimiliki dibidang pariwisata adalah bekerja di Hotel Mercure Kuta Bali sebagai Chef de Partie.

Prof. Dr. A. A. Ngurah Anom Kumbara, MS adalah guru besar antropologi Fakultas Ilmu Budaya Unud. Antropolog yang menyelesaikan pendidikan doktor di UGM ini mengajar di Prodi S-2 Kajian Pariwisata dan di Prodi Kajian Budaya (S2 dan S3). Fokus penelitiannya adalah masalah sosial budaya, konflik, multikultural. Email: anom_kumbara@yahoo.com

Dr. Ida Bagus Ketut Surya, SE., MM adalah dosen Prodi Magister Kajian Pariwisata Universitas Udayana. Selain itu, beliau juga aktif megajar sebagai dosen Program Studi Manajemen pada Fakultas Ekonomi dan Bisnis Universitas Udayana, Prodi Magister Manajemen, Prodi Magister Akuntansi dan Prodi Doktor Ilmu Manajemen Universitas Udayana. Beliau lahir di Desa Lukluk, Kecamatan Mengwi, Kabupaten Badung. Program pendidikan yang ditempuh yaitu Sarjana (S1) di Manajemen Fakultas Ekonomi dan Bisnis Universitas Udayana, jenjang (S2) di Magister Manajemen Konsentrasi Bisnis Pariwisata di Universitas Udayana, dan jenjang Doktor ( 33 ) di Program Doktor Ilmu Manajemen Universitas Brawijaya Malang. Email: idabgssurya@yahoo.co.id 